\title{
Complex Dynamics of Sine Function using Jungck Ishikawa Iterates
}

\author{
Suman Pant \\ Research Scholar \\ G. B. Pant Eng. College, \\ Pauri Garhwal
}

\author{
Yashwant S.Chauhan, \\ Ph.D \\ Assistant Professor \\ G. B. Pant Eng. College, \\ Pauri Garhwal
}

\author{
Priti Dimri, Ph.D \\ Asso. Professor and Head \\ G. B. Pant Eng. College, \\ Pauri Garhwal
}

\begin{abstract}
The dynamics of transcendental function is one of emerging and interesting field of research nowadays. We introduce in this paper the complex dynamics of sine function of the type $\left\{\sin \left(\mathrm{z}^{\mathrm{n}}\right)-\mathrm{z}+\mathrm{c}=0\right\}$ and applied Jungck Ishikawa iteration to generate Relative Superior Mandelbrot set and Relative Superior Julia set. In order to solve this function by Jungck type iterative schemes, we write it in the form of $\mathrm{Sz}=\mathrm{Tz}$, where the function $\mathrm{T}, \mathrm{S}$ are defined as $\mathrm{Tz}=\sin \left(\mathrm{z}^{\mathrm{n}}\right)+\mathrm{c}$ and $\mathrm{Sz}=\mathrm{z}$. Only mathematical explanations are derived by applying Jungck Ishikawa Iteration for transcendental function in the literature but in this paper we have generated relative Mandelbrot sets and Relative Julia sets.
\end{abstract}

\section{Keywords}

Complex dynamics, Relative Superior Mandelbrot set, Relative Julia set, Jungck Ishikawa Iteration

\section{INTRODUCTION}

The study of dynamical behavior of the transcendental functions was initiated by Fatou [12]. For transcendental function, points with unbounded orbits are not in Fatou sets but they must lie in Julia sets. Attractive points of a function have a basin of attraction, which may be disconnected.

A point $\mathrm{z}$ in Julia for sine function has an orbit that satisfies

$|\operatorname{Imz}|>=50$.

The iteration of complex analytic function (f) decompose the complex plane into two disjoint sets

1. Stable Fatou sets on which the iterations are well behaved.

2. Julia sets on which the map is chaotic.

In this past literature the sine function was considered of the following forms:

(i) $\sin \left(\mathrm{z}^{\mathrm{n}}\right)+\mathrm{c}=0$

(ii) $(\sin \mathrm{z}+\mathrm{c})^{\mathrm{n}}=0$

We are using in our paper sine function of the type $\sin \left(\mathrm{z}^{\mathrm{n}}\right)-\mathrm{z}+\mathrm{c}=0$ where $\mathrm{n} \geq 2$ and applied Jungck Ishikawa iterates to develop fractal images of this transcendental

function. Escape criteria of polynomials are used to generate Relative Superior Mandelbrot Sets and Relative Superior Julia Sets. Our results are different from existing results in literature.

\section{PRELIMINARIES}

The process of generating fractal images from $\mathrm{z} \rightarrow \sin \left(\mathrm{z}^{\mathrm{n}}\right)-\mathrm{z}+\mathrm{c}$ is similar to the one employed for the selfsquared function [17]. Briefly, this process consists of iterating this function up to $\mathrm{N}$ times.

Starting from a value $\mathrm{z}_{0}$ we obtain $\mathrm{z} 1, \mathrm{z}_{2}, \mathrm{z}_{3}, \mathrm{z}_{4} \ldots$ by applying the transformation $\mathrm{z} \rightarrow \sin \left(\mathrm{z}^{\mathrm{n}}\right)-\mathrm{z}+\mathrm{c}$

\subsection{Ishikawa Iteration [2]}

Let $\mathrm{X}$ is a subset of real or complex numbers and $\mathrm{T}: \mathrm{X} \rightarrow \mathrm{X}$ for $x_{0} \in X$, we have the sequences $\left\{x_{n}\right\}$ and $\left\{y_{n}\right\}$ in $X$ in the following manner:

$x_{n+1}=\alpha_{n} T y_{n}+\left(1-\alpha_{n}\right) x_{n}$

$\mathrm{y}_{\mathrm{n}}=\beta_{\mathrm{n}} \mathrm{T} \mathrm{x}_{\mathrm{n}}+\left(1-\beta_{\mathrm{n}}\right) \mathrm{x}_{\mathrm{n}}$

where $0 \leq \beta_{\mathrm{n}} \geq 1$ and $0 \leq \alpha_{\mathrm{n}} \geq 1$ and $\alpha_{\mathrm{n}} \& \beta_{\mathrm{n}}$ both convergent to non zero number.

\subsection{Definition [1]}

The sequences $\left\{x_{n}\right\}$ and $\left\{y_{n}\right\}$ constructed above is called Ishikawa sequences of iteration or relative superior sequences of iterates. We denote it by $\left(x_{0}, \alpha_{n}, \beta_{n}, t\right)$. Notice that RSO $\left(\mathrm{x}_{0}, \alpha_{\mathrm{n}}, \beta_{\mathrm{n}}, \mathrm{t}\right)$ with $\beta_{\mathrm{n}}=1$ is $\operatorname{RSO}\left(\mathrm{x}_{0}, \alpha_{\mathrm{n}}, \mathrm{t}\right)$ i.e. Mann's orbit and if we place $\alpha_{n}=\beta_{n}=1$ then $\operatorname{RSO}\left(x_{0}, \alpha_{n}, \beta_{n}, t\right)$ reduces to $\mathrm{O}\left(\mathrm{x}_{0}, \mathrm{t}\right)$.We remark that Ishikawa orbit $\operatorname{RSO}\left(\mathrm{x}_{0}, \alpha_{\mathrm{n}}, \beta_{\mathrm{n}}, \mathrm{t}\right)$ with $\beta_{n}=1 / 2 \quad$ is Relative superior orbit. Now we define Julia set for function with respect to Ishikawa iterates. We call them as Relative Superior Julia sets.

\subsection{Definition [1]}

The set of points SK whose orbits are bounded under Relative superior iteration of function Q (z) is called Relative Superior Julia sets. Relative Superior Julia set of $Q$ is a boundary of Julia set RSK.

\subsection{Jungck Ishikawa Iteration [2]}

Let $(X,\|\|$.$) be a Banach space and Y$ an arbitrary set. Let $S$, $\mathrm{T}: \mathrm{Y} \rightarrow \mathrm{X}$ be two non self-mappings such that $\mathrm{T}(\mathrm{Y}) \subseteq \mathrm{S}(\mathrm{Y})$, $\mathrm{S}(\mathrm{Y})$ is a complete subspace of $\mathrm{X}$ and $\mathrm{S}$ is injective. Then for $\mathrm{x}_{0} \in \mathrm{Y}$, define the sequence $\left\{\mathrm{S}_{\mathrm{n}}\right\}$ iteratively by

$S \mathrm{x}_{\mathrm{n}+1}=\alpha_{\mathrm{n}} \mathrm{T} \mathrm{y}_{\mathrm{n}}+\left(1-\alpha_{\mathrm{n}}\right) \mathrm{Sx_{n }}$

$S y_{n}=\beta_{n} T x_{n}+\left(1-\beta_{n}\right) S x_{n}$

where $0 \leq \beta_{\mathrm{n}} \geq 1$ and $0 \leq \alpha_{\mathrm{n}} \geq 1$ and $\alpha_{\mathrm{n}} \& \beta_{\mathrm{n}}$ both convergent to non zero number. 


\section{FIXED POINTS}

\subsection{Fixed points of quadratic function}

Table 1: Orbit of $F(z)$ for $\left(z_{0}=0.1625+0.8125 i\right)$ at $\alpha=0.5$, $\beta=0.5, \mathbf{c}=0.1$

\begin{tabular}{|c|c|c|}
\hline $\begin{array}{c}\text { No. of } \\
\text { iterations }\end{array}$ & $|\mathrm{Sz}|$ & $|\mathrm{Tz}|$ \\
\hline 1 & 0.31249 & 0.43321 \\
\hline 2 & 0.04783 & 0.01441 \\
\hline 3 & 0.01464 & 0.07266 \\
\hline 4 & 0.05462 & 0.09546 \\
\hline 5 & 0.07897 & 0.10403 \\
\hline 6 & 0.09330 & 0.10803 \\
\hline 7 & 0.10160 & 0.11011 \\
\hline 8 & 0.10636 & 0.11125 \\
\hline 9 & 0.10909 & 0.11188 \\
\hline 10 & 0.11064 & 0.11224 \\
\hline 11 & 0.11153 & 0.11244 \\
\hline 12 & 0.11203 & 0.11255 \\
\hline 13 & 0.11232 & 0.11262 \\
\hline 14 & 0.11249 & 0.11265 \\
\hline 15 & 0.11258 & 0.11267 \\
\hline 16 & 0.11263 & 0.11269 \\
\hline 17 & 0.11266 & 0.11269 \\
\hline 18 & 0.11268 & 0.11270 \\
\hline 19 & 0.11269 & 0.11270 \\
\hline 20 & 0.11269 & 0.11270 \\
\hline 21 & 0.11270 & 0.11270 \\
\hline 22 & 0.11270 & 0.11270 \\
\hline 23 & 0.11270 & 0.11270 \\
\hline 24 & 0.11270 & 0.11270 \\
\hline & & \\
\hline
\end{tabular}

Here we observe that the value converges to a fixed point after 21 iterations.

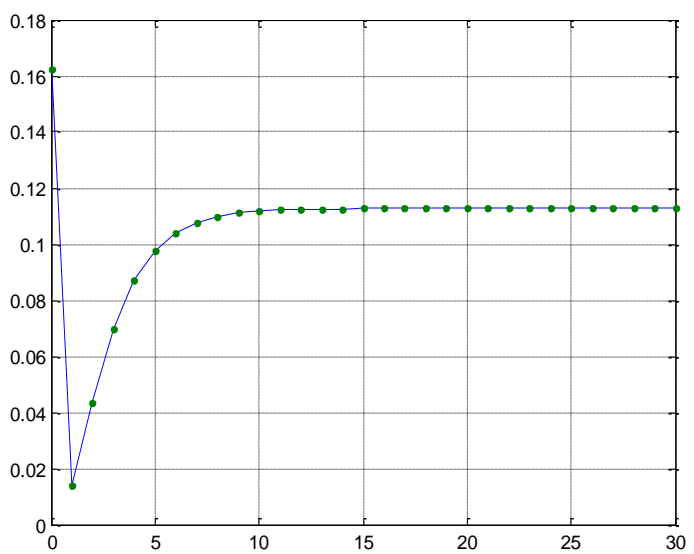

Figure 1: Orbit of $\mathrm{F}(\mathrm{x})$ for $\left(\mathrm{z}_{\mathrm{o}}=0.1625+0.8125 \mathrm{i}\right)$ at $\alpha=0.5$, $\beta=0.5, \mathrm{c}=0.1$

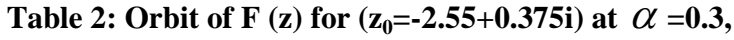

$$
\beta=0.7, \mathbf{c}=0.1
$$

\begin{tabular}{|c|c|c|}
\hline $\begin{array}{c}\text { No. of } \\
\text { iterations }\end{array}$ & $|\mathrm{Sz}|$ & $|\mathrm{Tz}|$ \\
\hline 1 & 0.27560 & 2.46585 \\
\hline 2 & 0.74621 & 1.37485 \\
\hline
\end{tabular}

\begin{tabular}{|c|c|c|}
3 & 0.72702 & 0.55117 \\
\hline 4 & 0.48395 & 0.17341 \\
\hline 5 & 0.15496 & 0.02913 \\
\hline 6 & 0.07996 & 0.09661 \\
\hline 7 & 0.09854 & 0.10888 \\
\hline 8 & 0.10783 & 0.11155 \\
\hline 9 & 0.1111 & 0.11233 \\
\hline 10 & 0.11218 & 0.11258 \\
\hline 11 & 0.11253 & 0.11266 \\
\hline 12 & 0.11265 & 0.11269 \\
\hline 13 & 0.11268 & 0.11270 \\
\hline 14 & 0.11270 & 0.11270 \\
\hline 15 & 0.11270 & 0.11270 \\
\hline 16 & 0.11270 & 0.11270 \\
\hline 17 & 0.11270 & 0.11270 \\
\hline 18 & 0.11270 & 0.11270 \\
\hline 19 & 0.11270 & 0.11270 \\
\hline 20 & 0.11270 & 0.11270 \\
\hline
\end{tabular}

Here we observe that the value converges to a fixed point after 14 iterations

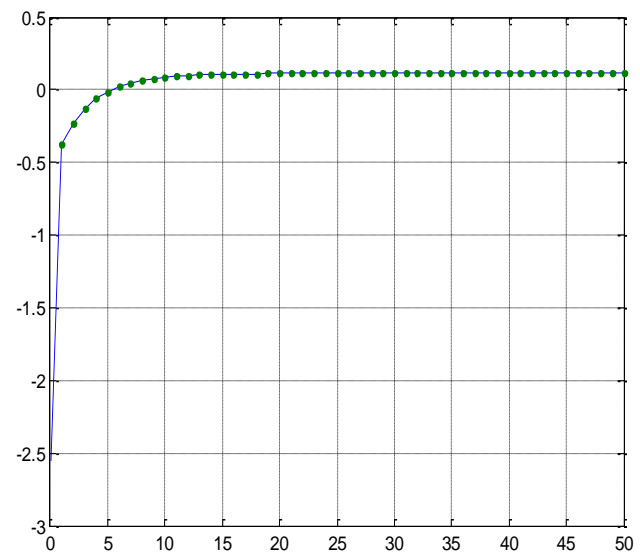

Figure 2. Orbit of $\mathrm{F}(\mathrm{x})$ for $\left(\mathrm{z}_{0}=-\mathbf{2 . 5 5 + 0 . 3 7 5 i )}\right.$ at $\alpha=0.3$, $\beta=0.7, \mathbf{c}=0.1$

Table 3: Orbit of $\mathbf{F}(\mathrm{z})$ for $\left(\mathrm{z}_{0}=-\mathbf{0 . 1 3 7 5 - 0 . 0 6 2 5 i}\right)$ at $\alpha=\mathbf{0 . 5}$, $\beta=0.8, \mathbf{c}=0.1$

\begin{tabular}{|c|c|c|}
\hline $\begin{array}{c}\text { No. of } \\
\text { iterations }\end{array}$ & $|\mathrm{Sz}|$ & $|\mathrm{Tz}|$ \\
\hline 140 & 0.11269 & 0.1127 \\
\hline 141 & 0.11269 & 0.1127 \\
\hline 142 & 0.11269 & 0.1127 \\
\hline 143 & 0.11269 & 0.1127 \\
\hline 144 & 0.11269 & 0.1127 \\
\hline 145 & 0.11269 & 0.1127 \\
\hline 146 & 0.11270 & 0.1127 \\
\hline 147 & 0.11270 & 0.1127 \\
\hline 148 & 0.11270 & 0.1127 \\
\hline 149 & 0.11270 & 0.1127 \\
\hline 150 & 0.11270 & 0.1127 \\
\hline
\end{tabular}

Here we skipped 139 iterations and observed that the value converges to a fixed point after 146 iterations. 


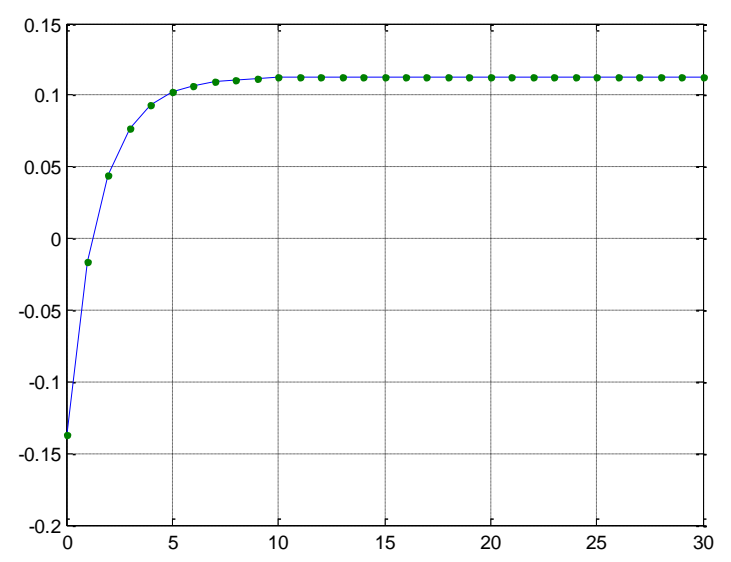

Figure 3: Orbit of $\mathrm{F}(\mathrm{z})$ for $\left(\mathrm{z}_{\mathbf{0}}=-\mathbf{0 . 1 3 7 5 - 0 . 0 6 2 5 i}\right)$ at $\alpha=0.5$,

$$
\beta=0.8, \mathbf{c}=0.1
$$

\subsection{Fixed points of cubic function}

Table 1: Orbit of $\mathrm{F}(\mathrm{z})$ for $\left(\mathrm{z}_{0}=-\mathbf{0 . 6 1 2 5 + 0 i}\right)$ at $\alpha=0.5$,

$$
\beta=0.5, \mathbf{c}=0.1
$$

\begin{tabular}{|c|c|c|}
\hline $\begin{array}{c}\text { No. of } \\
\text { iterations }\end{array}$ & $|\mathrm{Sz}|$ & \\
\hline 1 & 0.09375 & 0.08144 \\
\hline 2 & 0.09884 & 0.10013 \\
\hline 3 & 0.10053 & 0.10098 \\
\hline 4 & 0.10093 & 0.10103 \\
\hline 5 & 0.10101 & 0.10103 \\
\hline 6 & 0.10103 & 0.10103 \\
\hline 7 & 0.10103 & 0.10103 \\
\hline 8 & 0.10103 & 0.10103 \\
\hline 9 & 0.10103 & 0.10103 \\
\hline 10 & 0.10103 & 0.10103 \\
\hline
\end{tabular}

Here we observe that the value converges to a fixed point after 6 iterations.

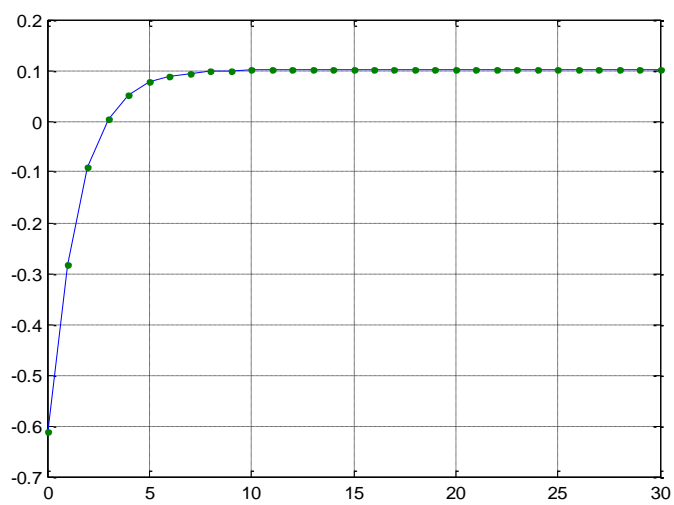

Figure 1 Orbit of $\mathrm{F}(\mathrm{z})$ for $\left(\mathrm{z}_{\mathbf{0}}=-\mathbf{- 0 . 6 1 2 5 + 0 i}\right)$ at $\alpha=0.5$, $\beta=0.5, \mathbf{c}=0.1$
Table 2: Orbit of $F(z)$ for $\left(z_{0}=-0.2625+1.10625 i\right)$ at

\begin{tabular}{|c|c|c|}
\hline $\begin{array}{c}\text { No. of } \\
\text { iterations }\end{array}$ & $|\mathrm{Sz}|$ & $|\mathrm{Tz}|$ \\
\hline 1 & 0.02500 & 0.04437 \\
\hline 2 & 0.06846 & 0.03949 \\
\hline 3 & 0.08382 & 0.05806 \\
\hline 4 & 0.08882 & 0.08958 \\
\hline 5 & 0.09342 & 0.09785 \\
\hline 6 & 0.09676 & 0.10012 \\
\hline 7 & 0.09875 & 0.10076 \\
\hline 8 & 0.09984 & 0.10094 \\
\hline 9 & 0.10042 & 0.10100 \\
\hline 10 & 0.10072 & 0.10102 \\
\hline 11 & 0.10087 & 0.10103 \\
\hline 12 & 0.10095 & 0.10103 \\
\hline 13 & 0.10099 & 0.10103 \\
\hline 14 & 0.10101 & 0.10103 \\
\hline 15 & 0.10102 & 0.10103 \\
\hline 16 & 0.10103 & 0.10103 \\
\hline 17 & 0.10103 & 0.10103 \\
\hline 18 & 0.10103 & 0.10103 \\
\hline 19 & 0.10103 & 0.10103 \\
\hline 20 & 0.10103 & 0.10103 \\
\hline
\end{tabular}
$\alpha=0.3, \beta=0.7, \mathbf{c}=0.1$

Here we observe that the value converges to a fixed point after 16 iterations.

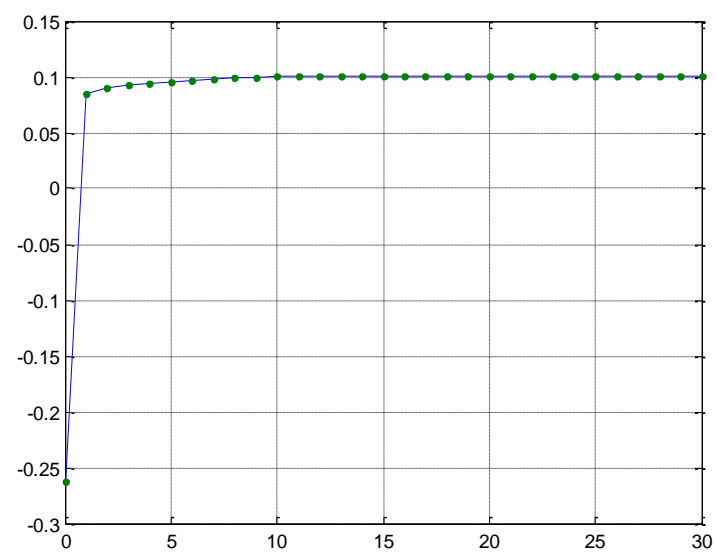

Figure 2: Orbit of $F(z)$ for $\left(z_{0}=-0.2625+1.10625 i\right)$ at $\alpha=0.3, \beta=0.7, \mathbf{c}=0.1$ 
Table 3: Orbit of $F(z)$ for $\left(z_{0}=0.1875+0.175 i\right)$ at $\alpha=0.5$, $\beta=0.8, c=0.1$

\begin{tabular}{|c|c|c|}
\hline $\begin{array}{c}\text { No. of } \\
\text { iterations }\end{array}$ & $|\mathrm{Sz}|$ & $|\mathrm{Tz}|$ \\
\hline 1 & 1.10625 & -0.73928 \\
\hline 2 & 0.13639 & -0.1472 \\
\hline 3 & 0.12193 & 0.02143 \\
\hline 4 & 0.11184 & 0.07494 \\
\hline 5 & 0.1062 & 0.09209 \\
\hline 6 & 0.10355 & 0.09787 \\
\hline 7 & 0.10232 & 0.0999 \\
\hline 8 & 0.10172 & 0.10063 \\
\hline 9 & 0.10142 & 0.10089 \\
\hline 10 & 0.10125 & 0.10098 \\
\hline 11 & 0.10116 & 0.10101 \\
\hline 12 & 0.10111 & 0.10103 \\
\hline 13 & 0.10108 & 0.10103 \\
\hline 14 & 0.10106 & 0.10103 \\
\hline 15 & 0.10105 & 0.10103 \\
\hline 16 & 0.10104 & 0.10103 \\
\hline 17 & 0.10104 & 0.10103 \\
\hline 18 & 0.10103 & 0.10103 \\
\hline 19 & 0.10103 & 0.10103 \\
\hline 20 & 0.10103 & 0.10103 \\
\hline
\end{tabular}

Here we observe that the value converges to a fixed point after 18 iterations.

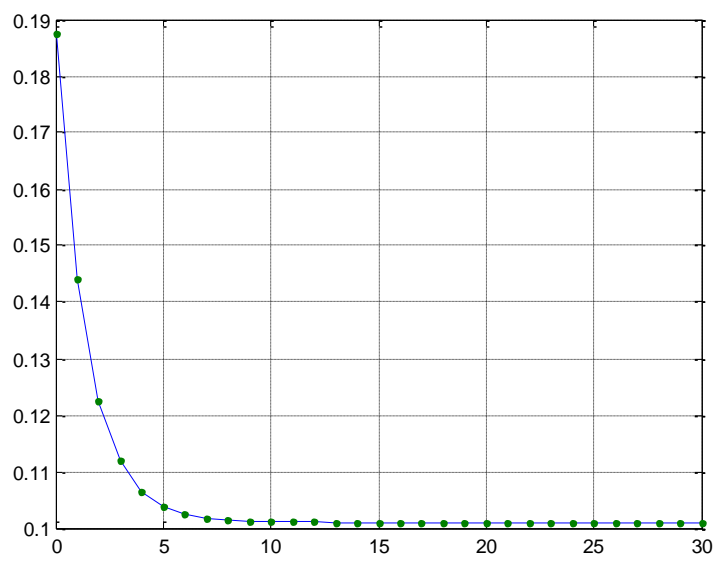

Figure 3: Orbit of $\mathbf{F}(\mathrm{z})$ for $\left(\mathrm{z}_{\mathbf{0}}=\mathbf{0 . 1 8 7 5 + 0 . 1 7 5 i )}\right.$ at $\alpha=0.5$, $\beta=0.8, \mathbf{c}=0.1$
3.3 Fixed points of biquadratic function Table 1: Orbit of $\mathrm{F}(\mathrm{z})$ for $\left(\mathrm{z}_{0}=\mathbf{0 . 0 3 7 5 + 0 . 6 2 5 i )}\right.$ at $\alpha=\mathbf{0 . 5}$, $\beta=0.5, \mathbf{c}=0.1$

\begin{tabular}{|c|c|c|}
\hline $\begin{array}{c}\text { No. of } \\
\text { iterations }\end{array}$ & $|\mathrm{Sz}|$ & $|\mathrm{Tz}|$ \\
\hline 1 & 0.00625 & 0.29254 \\
\hline 2 & 0.07642 & 0.09973 \\
\hline 3 & 0.09532 & 0.10004 \\
\hline 4 & 0.09914 & 0.10009 \\
\hline 5 & 0.09991 & 0.1001 \\
\hline 6 & 0.10006 & 0.1001 \\
\hline 7 & 0.10009 & 0.1001 \\
\hline 8 & 0.1001 & 0.1001 \\
\hline 9 & 0.1001 & 0.1001 \\
\hline 10 & 0.1001 & 0.1001 \\
\hline
\end{tabular}

Here we observe that the value converges to a fixed point after 8 iterations.

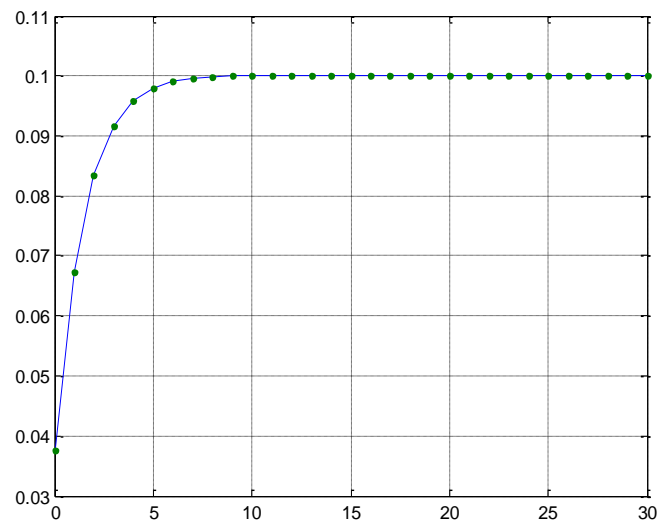

Figure 1: Orbit of $\mathbf{F}(\mathrm{z})$ for $\left(\mathrm{z}_{\mathbf{0}}=\mathbf{0 . 0 3 7 5}+\mathbf{0 . 6 2 5 i}\right)$ at $\alpha=0.5$, $\beta=0.5, \mathbf{c}=0.1$

Table 2: Orbit of $\mathbf{F}(\mathrm{z})$ for $\left(\mathrm{z}_{0}=\mathbf{0 . 1 - 0 . 3 i}\right)$ at $\alpha=0.3, \beta=0.7$, $c=0.1$

\begin{tabular}{|c|c|c|}
\hline $\begin{array}{c}\text { No. of } \\
\text { iterations }\end{array}$ & $|\mathrm{Sz}|$ & $|\mathrm{Tz}|$ \\
\hline 1 & 0.06875 & 1.46516 \\
\hline 2 & 0.48917 & 0.15118 \\
\hline 3 & 0.20888 & 0.08937 \\
\hline 4 & 0.05448 & 0.09998 \\
\hline 5 & 0.02276 & 0.10000 \\
\hline 6 & 0.06138 & 0.09999 \\
\hline 7 & 0.08071 & 0.10003 \\
\hline 8 & 0.09038 & 0.10006 \\
\hline 9 & 0.09523 & 0.10008 \\
\hline 10 & 0.09766 & 0.10009 \\
\hline 11 & 0.09888 & 0.10010 \\
\hline 12 & 0.09949 & 0.10010 \\
\hline
\end{tabular}




\begin{tabular}{|l|l|l|}
13 & 0.09979 & 0.10010 \\
\hline 14 & 0.09995 & 0.10010 \\
\hline 15 & 0.10002 & 0.10010 \\
\hline 16 & 0.10006 & 0.10010 \\
\hline 17 & 0.10008 & 0.10010 \\
\hline 18 & 0.10009 & 0.10010 \\
\hline 19 & 0.10010 & 0.10010 \\
\hline 20 & 0.10010 & 0.10010 \\
\hline
\end{tabular}

Here we observe that the value converges to a fixed point after 19 iterations.

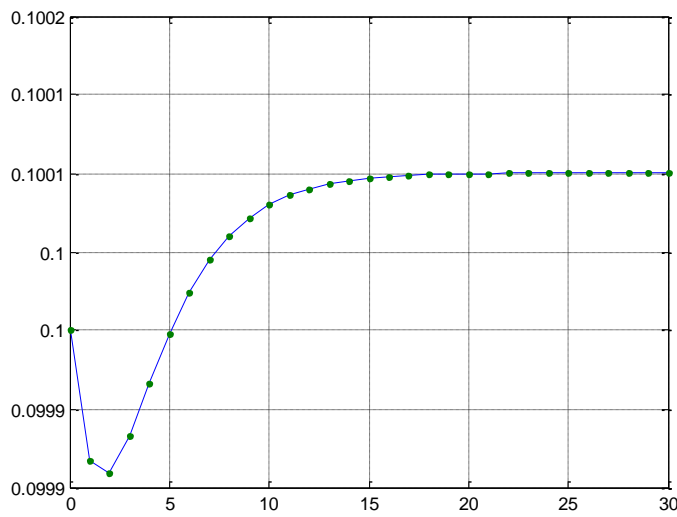

Figure 2: Orbit of $\mathbf{F}(\mathrm{z})$ for $\left(\mathrm{z}_{\mathbf{0}}=\mathbf{0 . 1 - 0 . 3 i}\right)$ at $\alpha=0.3$,

$$
\beta=0.7, \mathbf{c}=0.1
$$

Table 3: Orbit of $\mathbf{F}(\mathrm{z})$ for $\left(\mathrm{z}_{\mathbf{0}}=\mathbf{0 . 2 3 7 5 + 0 i}\right)$ at $\alpha=0.5$,

$$
\beta=0.8, \mathbf{c}=0.1
$$

\begin{tabular}{|c|c|c|}
\hline $\begin{array}{c}\text { No. of } \\
\text { iterations }\end{array}$ & $|\mathrm{Sz}|$ & $|\mathrm{Tz}|$ \\
\hline 1 & 0.26875 & 0.81993 \\
\hline 2 & 0.04699 & 0.09997 \\
\hline 3 & 0.06819 & 0.09994 \\
\hline 4 & 0.08093 & 0.10000 \\
\hline 5 & 0.08858 & 0.10004 \\
\hline 6 & 0.09318 & 0.10007 \\
\hline 7 & 0.09594 & 0.10008 \\
\hline 8 & 0.09760 & 0.10009 \\
\hline 9 & 0.09860 & 0.10009 \\
\hline 10 & 0.09920 & 0.10010 \\
\hline 11 & 0.09956 & 0.10010 \\
\hline 12 & 0.09978 & 0.10010 \\
\hline 13 & 0.09991 & 0.10010 \\
\hline 14 & 0.09998 & 0.10010 \\
\hline 15 & 0.10003 & 0.10010 \\
\hline 16 & 0.10006 & 0.10010 \\
\hline 17 & 0.10007 & 0.10010 \\
\hline 18 & 0.10009 & 0.10010 \\
\hline 19 & 0.10009 & 0.10010 \\
\hline 20 & 0.10009 & 0.10010 \\
\hline 21 & 0.10010 & 0.10010 \\
\hline 22 & 0.10010 & 0.10010 \\
\hline
\end{tabular}

\begin{tabular}{|l|l|l|}
23 & 0.10010 & 0.10010 \\
\hline 24 & 0.10010 & 0.10010 \\
\hline 25 & 0.10010 & 0.10010 \\
\hline
\end{tabular}

Here we observe that the value converges to a fixed point after 21 iterations.

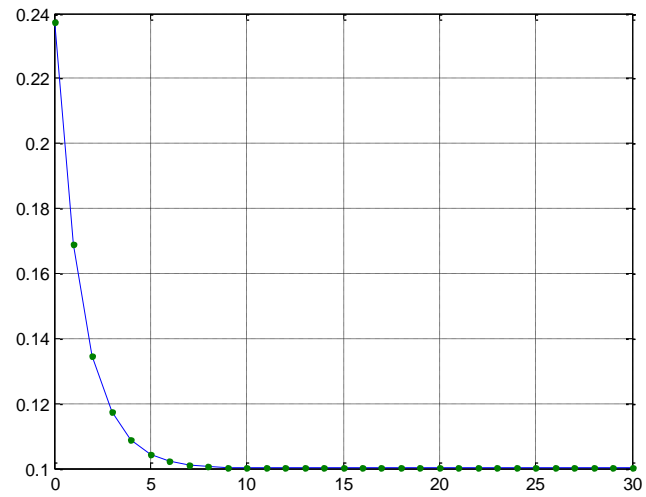

Figure 3: Orbit of $F(z)$ for $\left(z_{0}=0.2375+0 i\right)$ at $\alpha=0.5$,

$$
\beta=0.8, \mathbf{c}=0.1
$$

\section{GEOMETRY OF RELATIVE SUPERIOR MANDELBROT SETS AND RELATIVE SUPERIOR JULIA SETS Relative Superior Mandelbrot Sets}

- In case of quadratic function, the central body is divided into two parts. It is seen that the body is symmetric along the real axis only. Secondary lobes are very small initially for

$\alpha=1, \beta=1$. As the value is changed to $\alpha=0.3$ $\beta=0.7$, the central body is divided into four parts but the middle part is quite larger in comparison to the head and tail.

Secondary lobes seem to appear larger than initial stage.

- In case of cubic function, the central body is divided into two equal parts, each part have one major secondary lobe and many minor secondary lobes. It is seen that the body is symmetric along the both axes. For $\alpha=0.3, \beta=0.7$, the size of the major secondary lobes start enlarging and also a tiny bulb seems to occur along the real axis.

- In case of biquadratic function, the central body is divided into three parts, each part having one major secondary bulb along with large number of minor secondary bulbs. It is seen that the body is symmetric along the real axis only. For $\alpha=0.3, \beta=0.7$, the two of the major secondary lobes are same in size but one of them grows larger in size and undergoes bifurcation along the real axis.

\section{Relative Superior Julia Sets}

- Relative Superior Julia Sets for the transcendental function $\sin (\mathrm{z})$ appears to follow law of having $2 \mathrm{n}$ 
wings. These sets are symmetric along both the axes i.e. along real and imaginary axis.

- The Relative Superior Julia Sets for quadratic function is divided into four wings having black central body. These sets are symmetric along both the axes.

- The Relative Superior Julia Sets for Cubic function is divided into six wings having reflectional and rotational symmetry, along with a larger black region.

- The Relative Superior Julia Sets for biquadratic function is divided into eight wings possessing the reflectional and rotational symmetry, along with a larger escape region as compared to quadratic and cubic function.

- It is also observed from the graphical study of fixed points of Relative Superior Julia Sets that the convergence for

- $\alpha=0.3, \beta=0.7$ is quite fast for all polynomials in comparison to the convergence for $\alpha=0.5, \beta=0.8$.

\section{GENERATION OF RELATIVE}

\section{SUPERIOR MANDELBROT SETS}

We generated the Relative Superior Mandelbrot sets. We present here some beautiful filled Relative Superior Mandelbrot sets for quadratic, cubic and biquadratic function.

\subsection{Relative Superior Mandelbrot sets for Quadratic function}

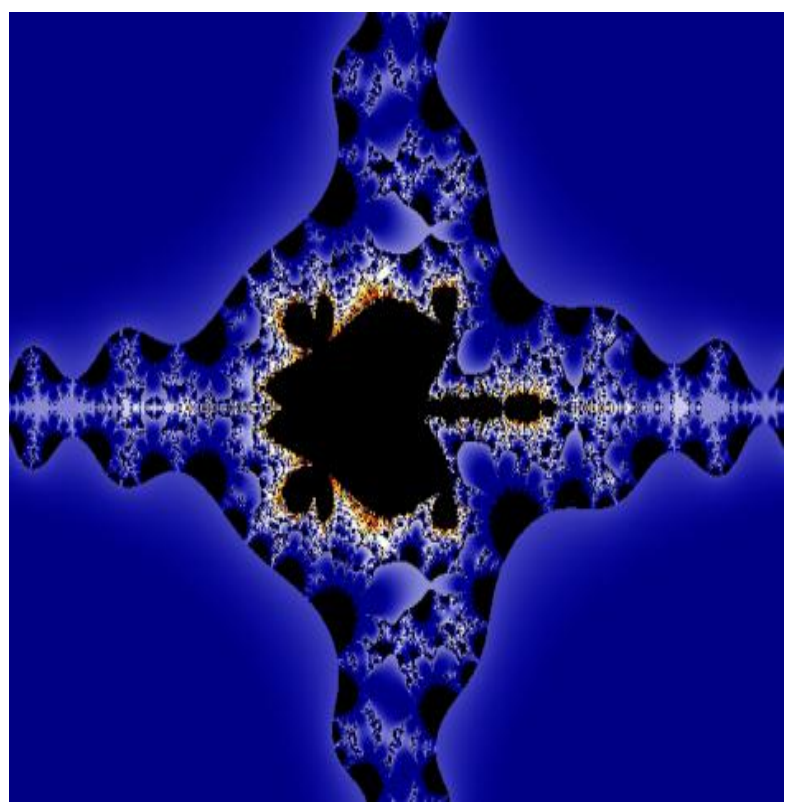

Figure 1: Relative Superior Mandelbrot Set for $\alpha=\beta=0.5 \& \mathbf{c}=\mathbf{- 0 . 1 6 2 5 + 0 . 8 1 2 5 i}$

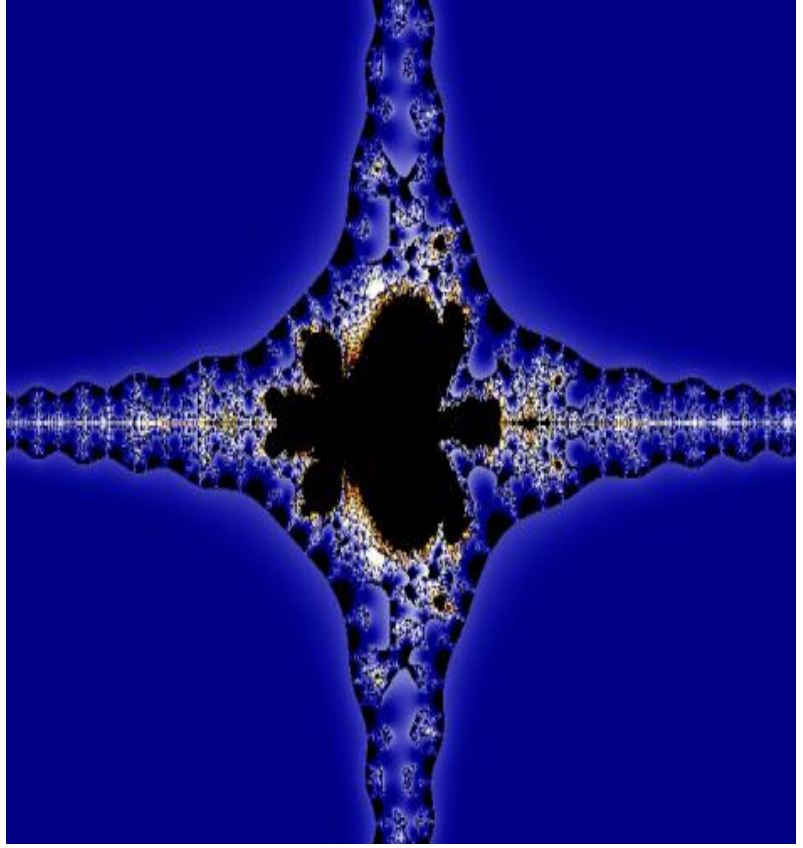

Figure 2: Relative Superior Mandelbrot Set for $\alpha=0.3$,

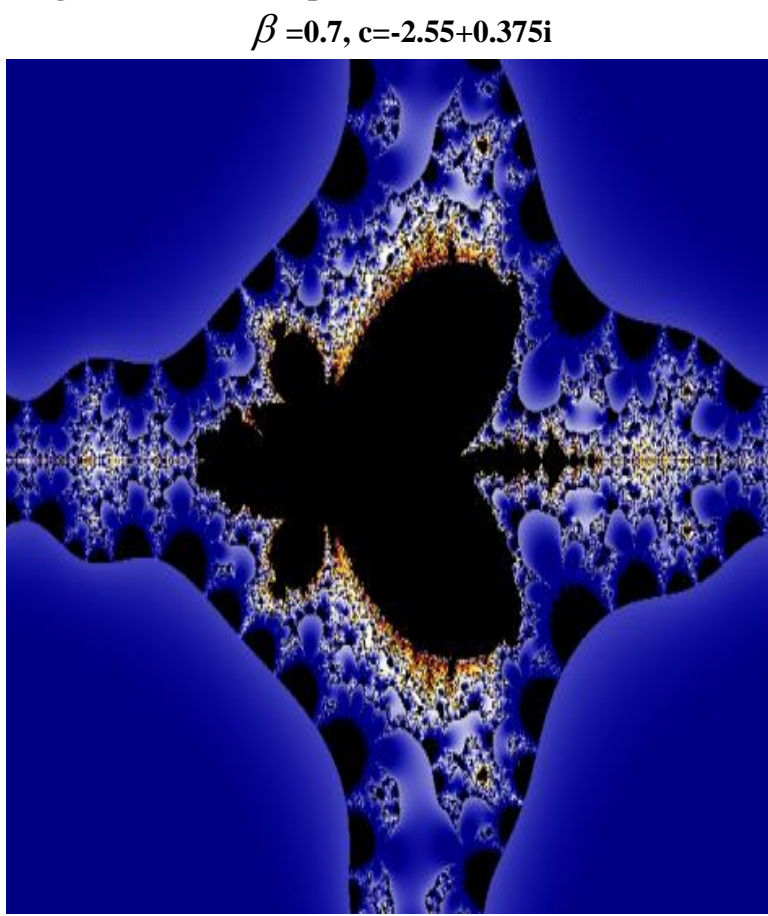

Figure 3: Relative Superior Mandelbrot Set for $\alpha=\mathbf{0 . 5}$, $\beta=0.8, \mathbf{c}=-0.1375-0.0625 \mathrm{i}$

\subsection{Relative Superior Mandelbrot Sets for Cubic function}




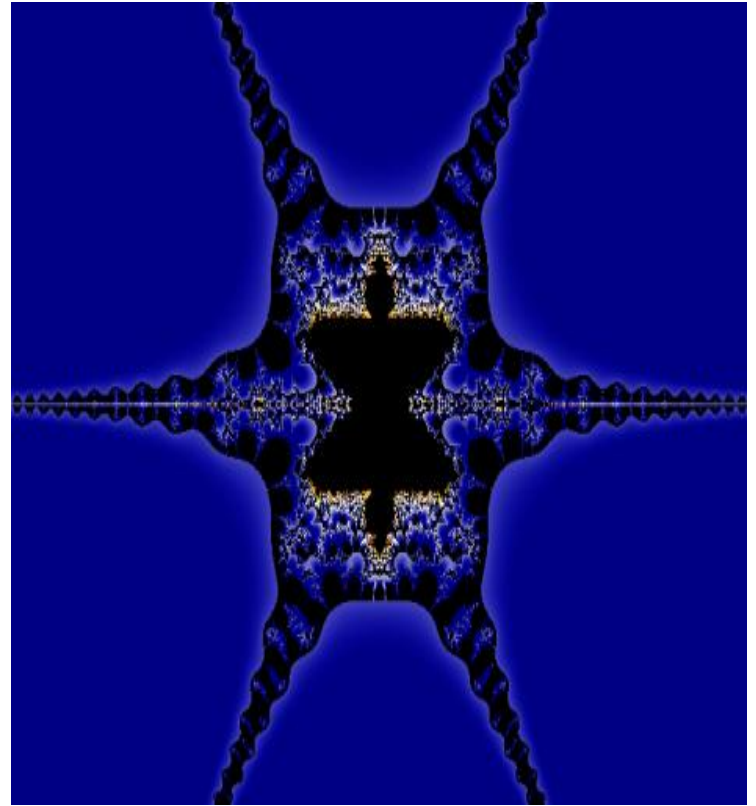

Figure 1: Relative Superior Mandelbrot Set for $\alpha=\beta=0.5, \mathbf{c}=-0.6125+0 \mathrm{i}$

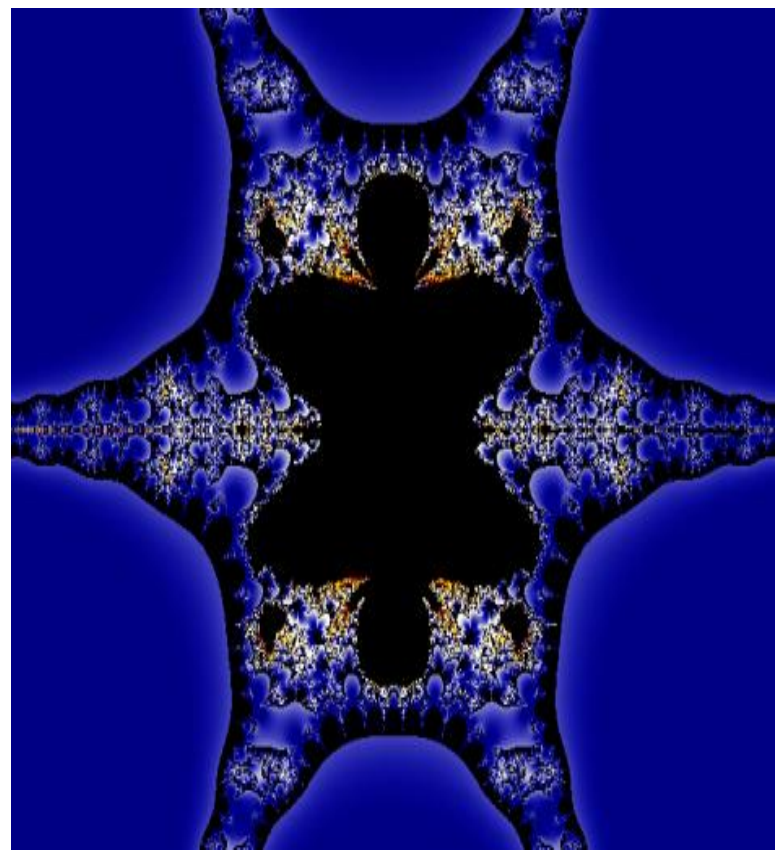

Figure 2: Relative Superior Mandelbrot Set for $\alpha=0.3$, $\beta=0.7, c=-0.2625+1.10625 i$

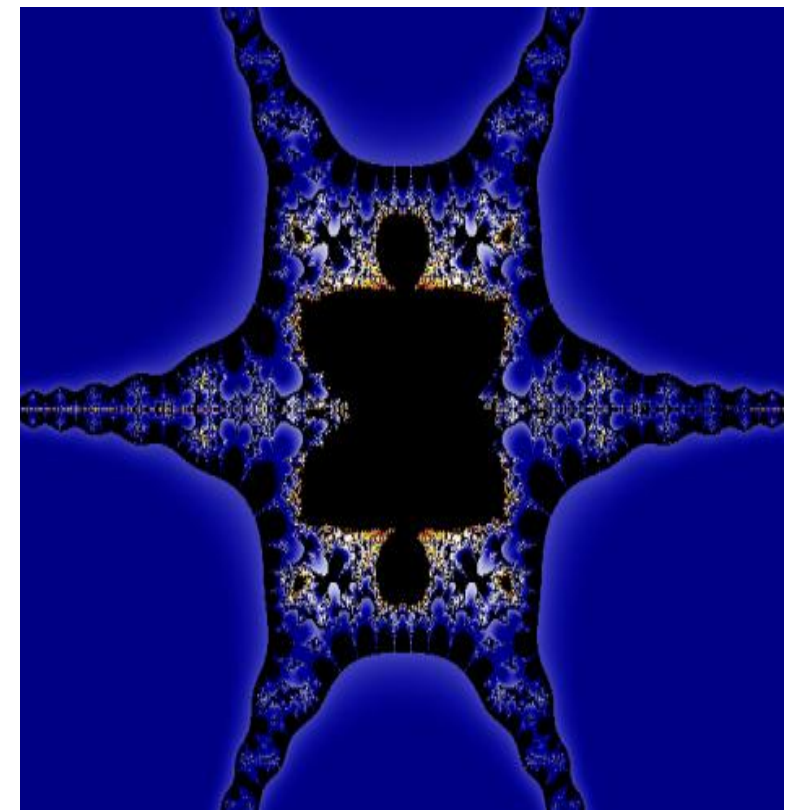

Figure 3: Relative Superior Mandelbrot Set for $\alpha=0.5$, $\beta=0.8, \mathbf{c}=0.1875+0.175 \mathrm{i}$

\subsection{Relative Superior Mandelbrot sets for} biquadratic function

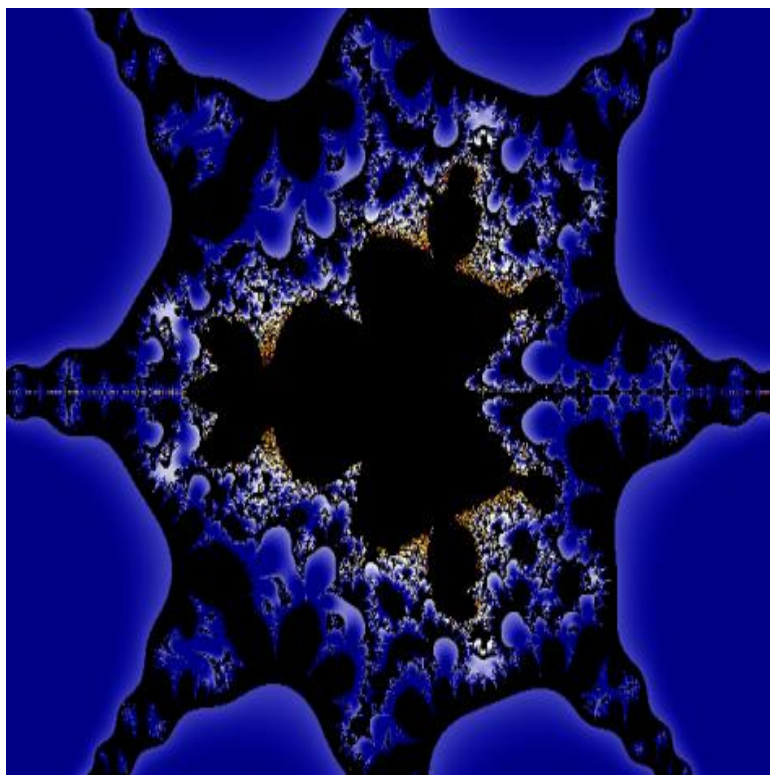

Figure 1: Relative Superior Mandelbrot Set for $\alpha=0.5$, $\beta=0.5, c=0.0375+0.625 i$ 


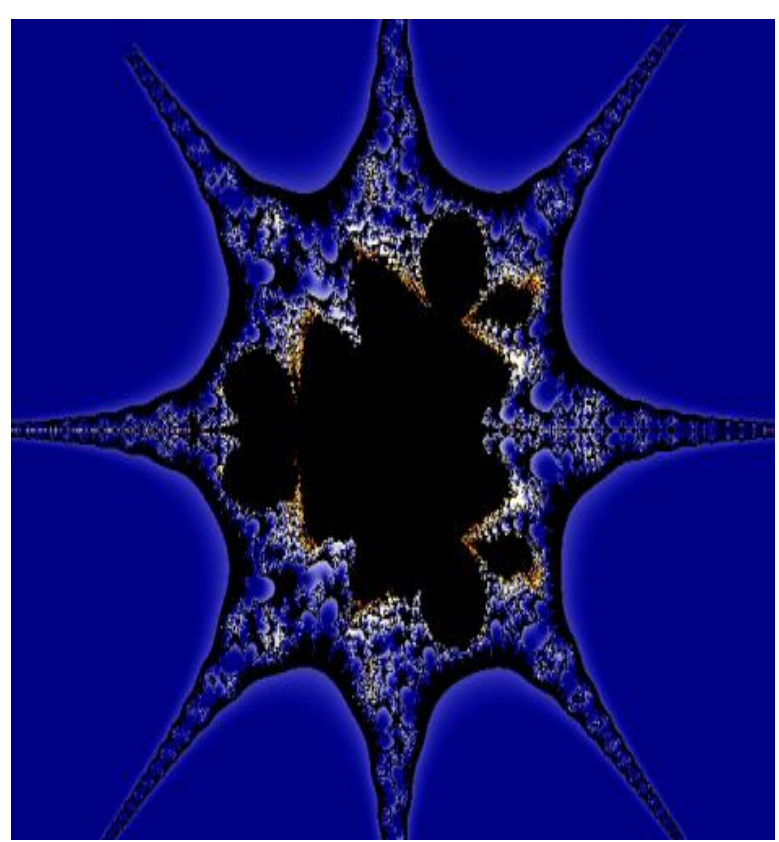

Figure 2: Relative Superior Mandelbrot Set for $\alpha=0.3$,

$$
\beta=0.7, \mathbf{c}=\mathbf{0 . 1 - 0 . 3 i}
$$

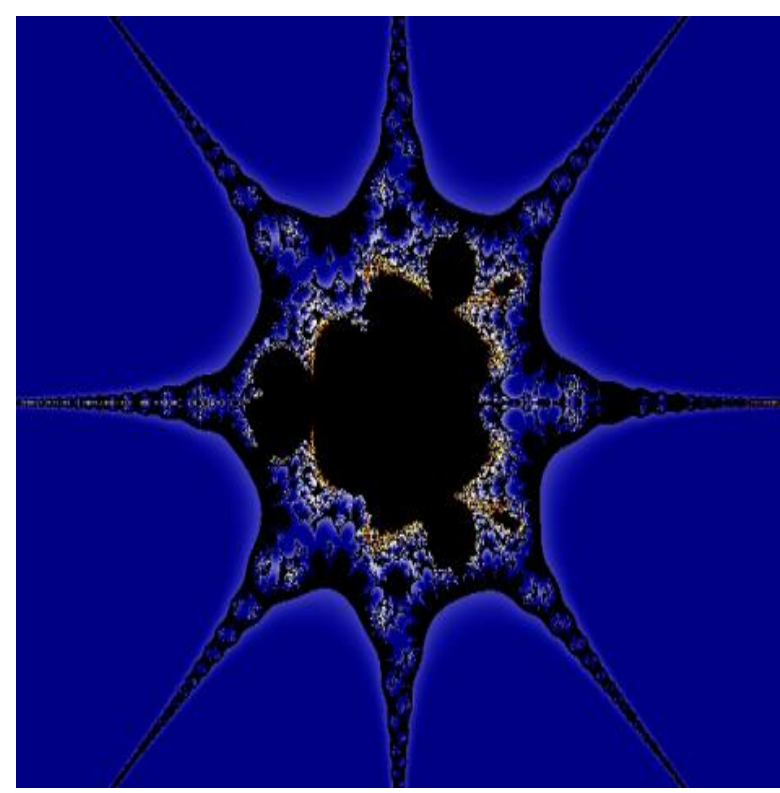

Figure 3: Relative Superior Mandelbrot Set for $\alpha=\mathbf{0 . 5}$,

$$
\beta=0.8, \mathbf{c}=0.2375+0 \mathrm{i}
$$

\section{GENERATION OF RELATIVE SUPERIOR JULIA SETS}

We generated the Relative Superior Julia sets. We have presented here some beautiful filled Relative Superior Julia sets for quadratic, cubic and biquadratic function.

\subsection{Relative Superior Julia sets for} Quadratic function

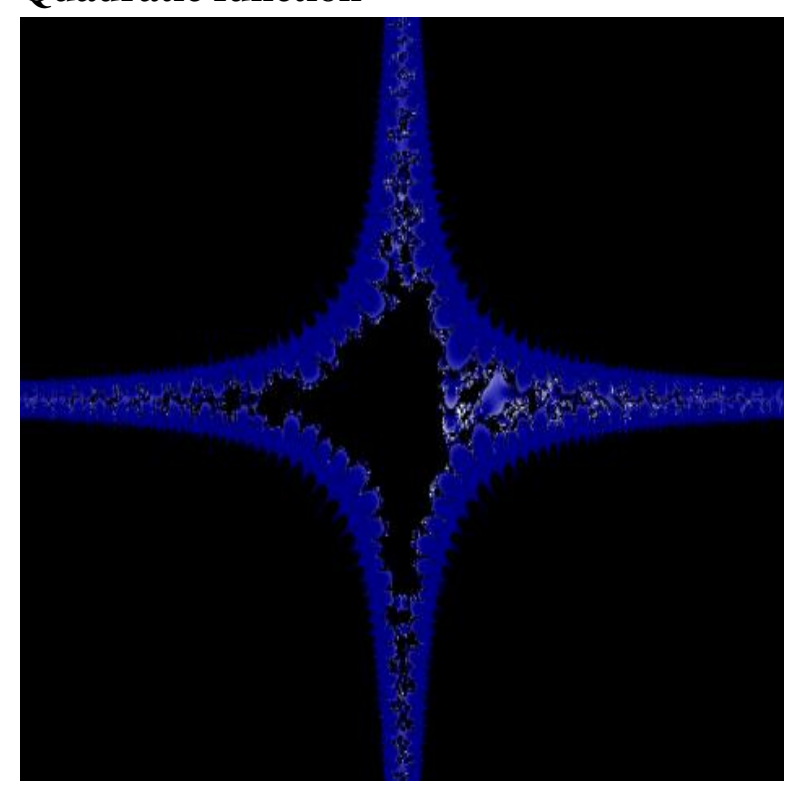

Figure 1: Relative Superior Julia Set for $\alpha=\beta=0.5$, $c=0.1625+0.8125 i$

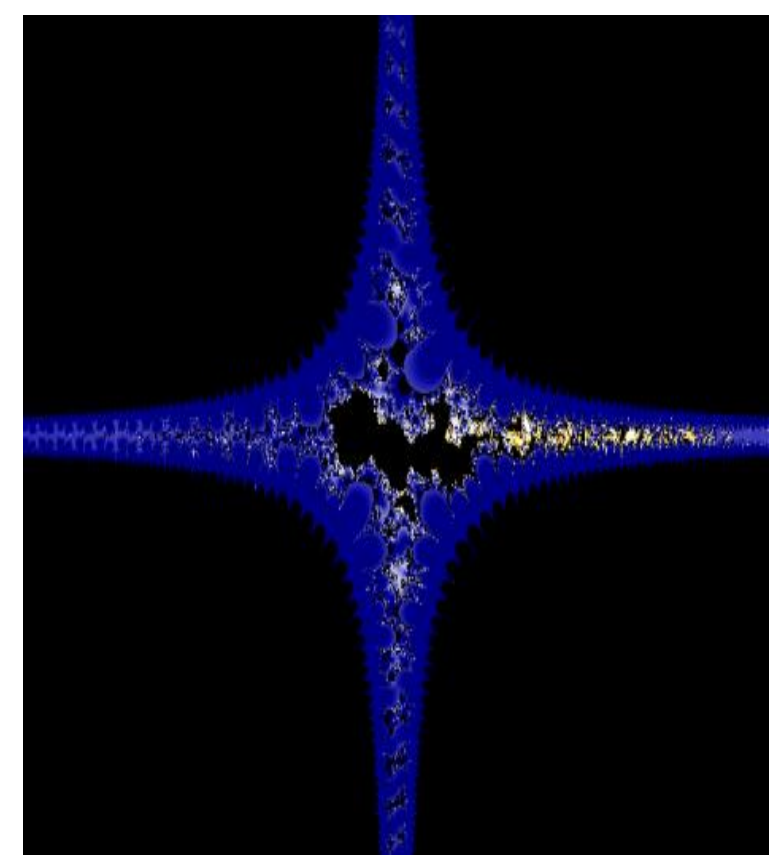

Figure 2: Relative Superior Julia Set for $\alpha=0.3, \beta=0.7$, $c=-2.55+0.375 i$ 


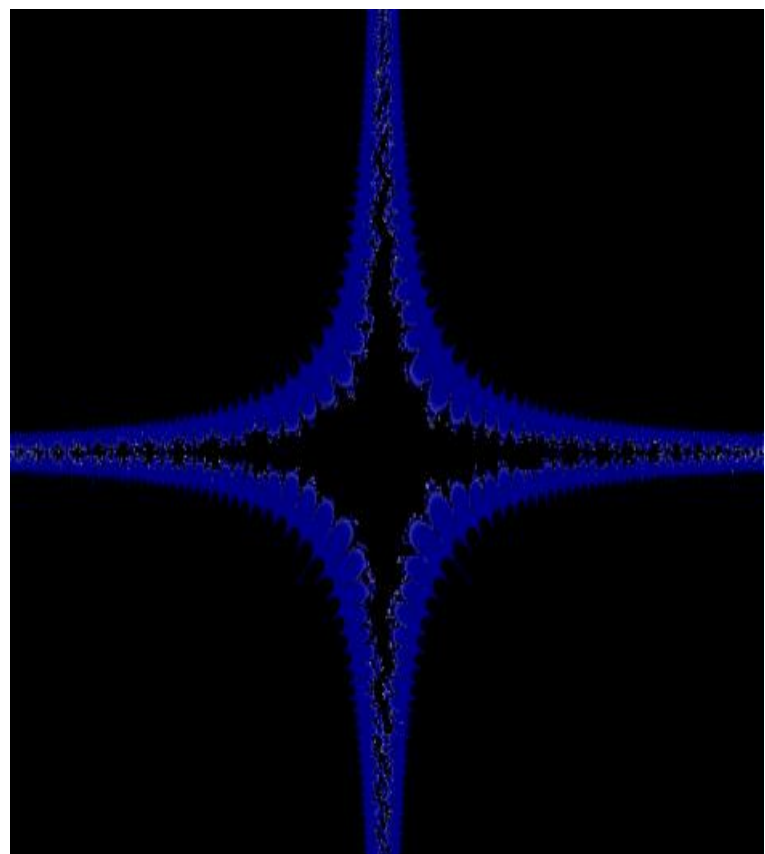

Figure 3: Relative Superior Julia Set for $\alpha=0.5, \beta=0.8$, c=-0.1375-0.0625i

5.2 Relative Superior Julia Sets for Cubic function

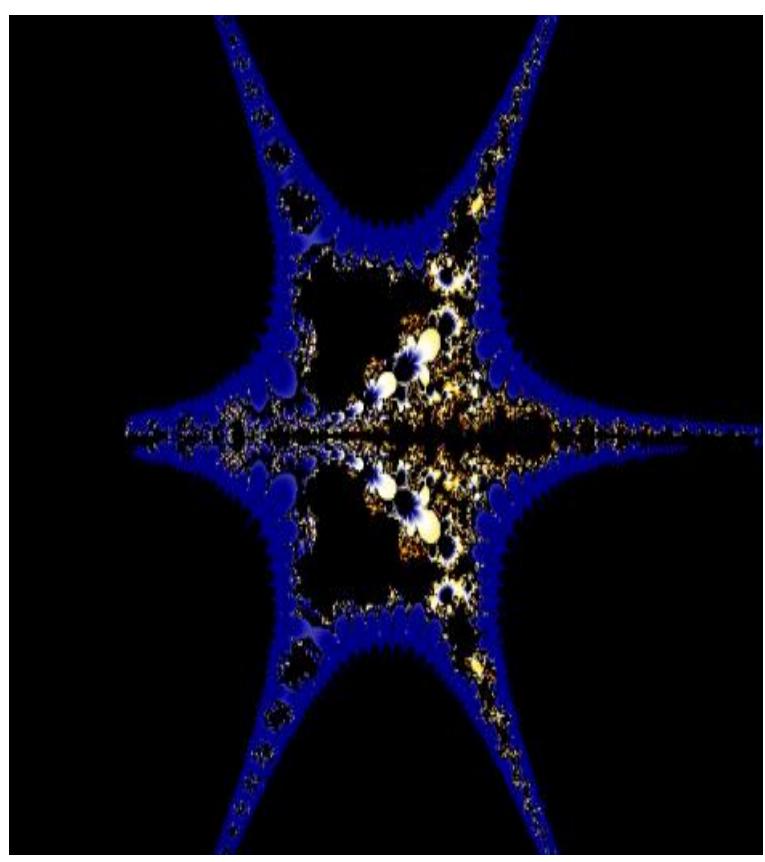

Figure 1: Relative Superior Julia Set for $\alpha=\beta=0.5$,

$$
c=-0.612+0 i
$$

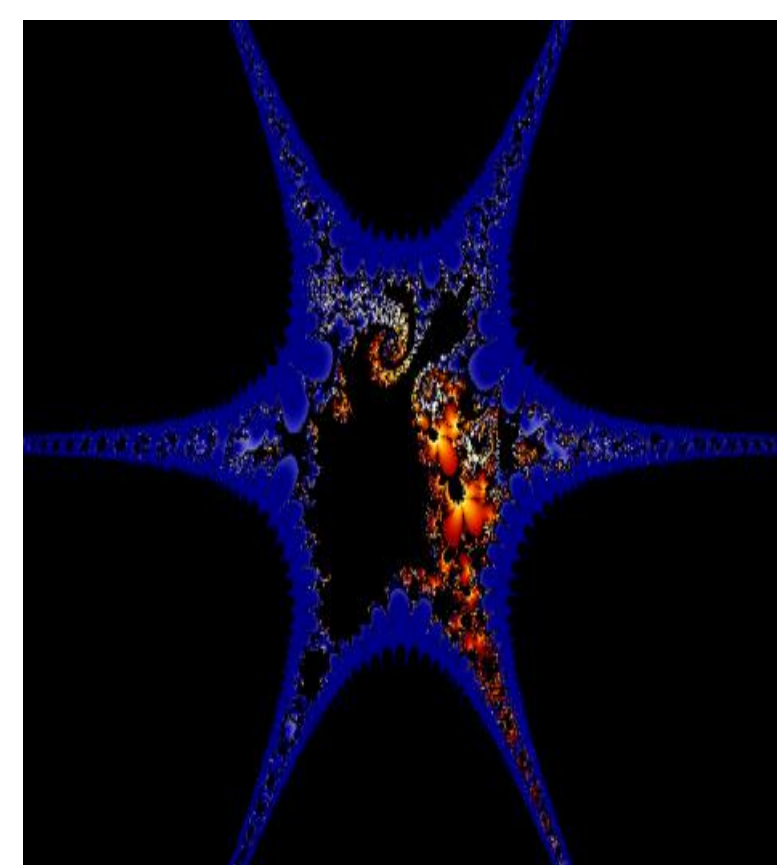

Figure 2: Relative Superior Julia Set for $\alpha=0.3, \beta=0.7$, $c=-\mathbf{0 . 2 6 2 5}+1.10625 \mathrm{i}$

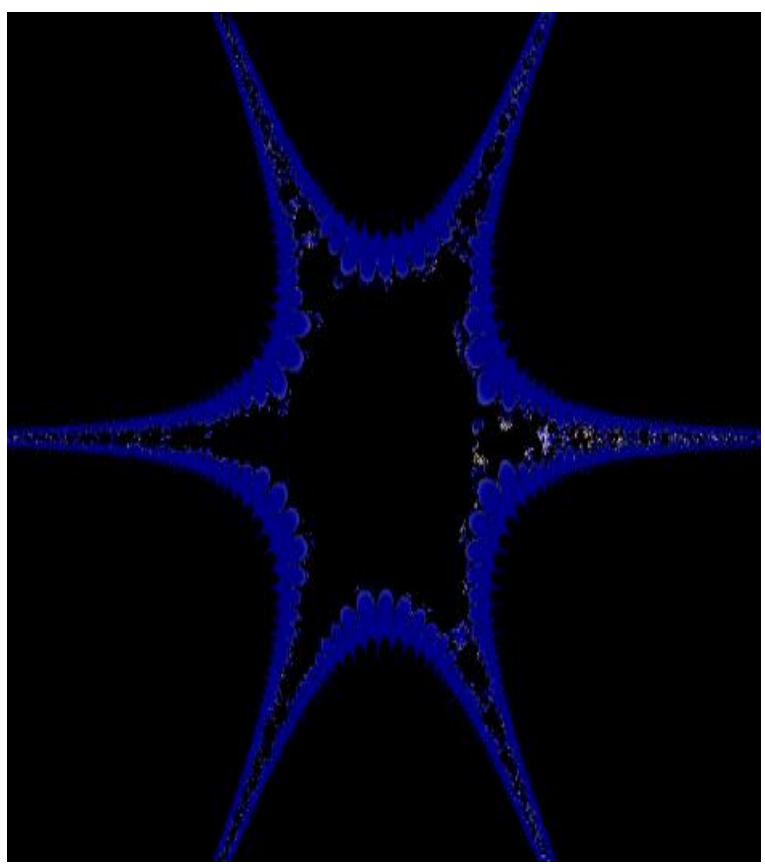

Figure 3: Relative Superior Julia Set for $\alpha=0.5, \beta=0.8$, $c=0.1875+0.175 i$

5.3 Relative Superior Julia sets for biquadratic function 


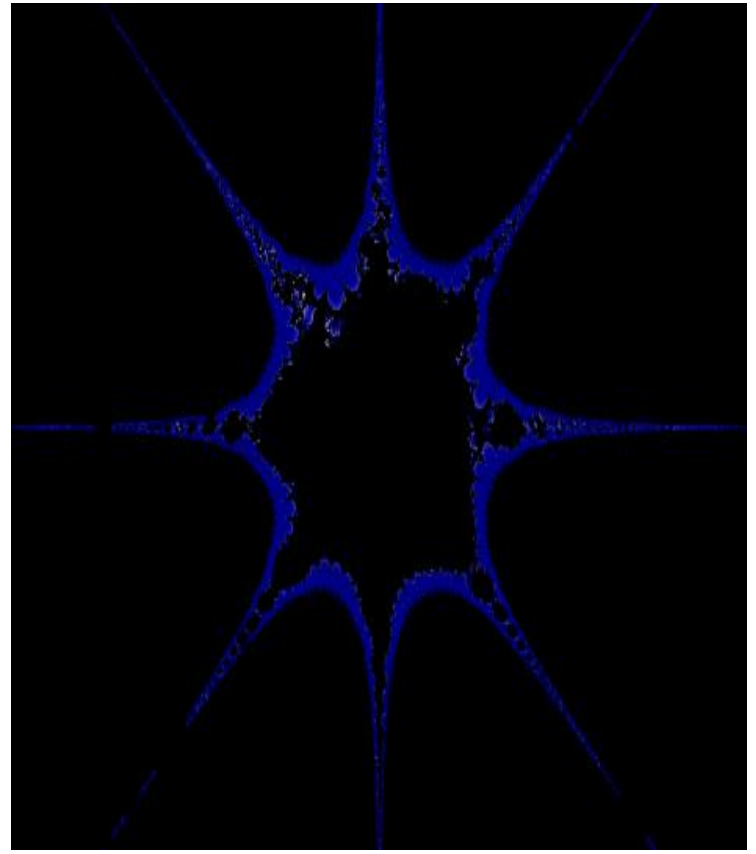

Figure 1: Relative Superior Julia Set for $\alpha=0.5, \beta=0.5$, $c=0.0375+0.625 i$

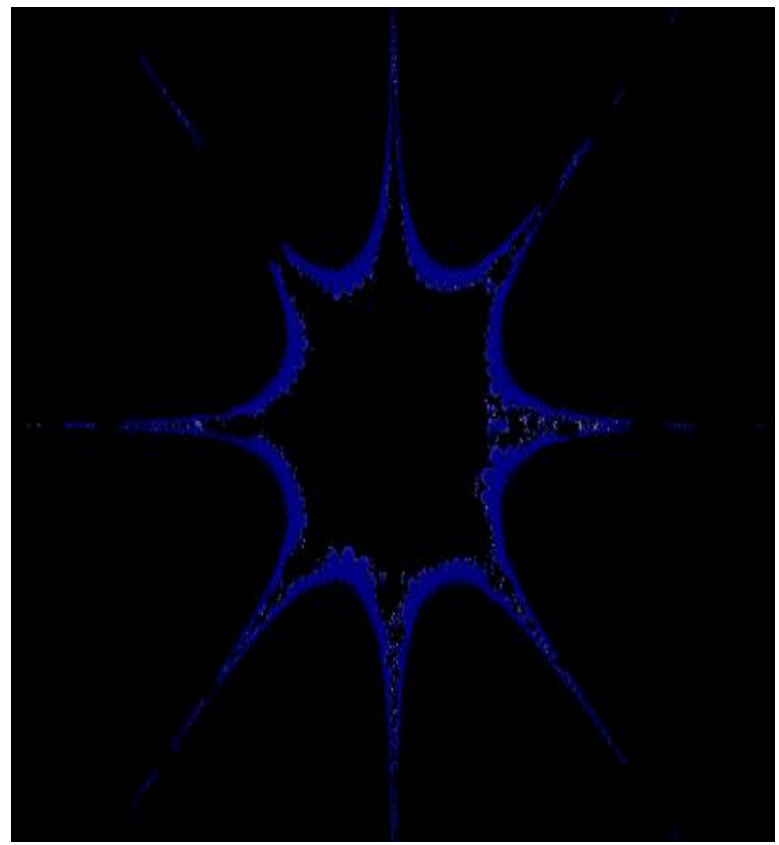

Figure 2: Relative Superior Julia Set for $\alpha=0.3, \beta=0.7$, c $=\mathbf{0 . 1}-\mathbf{0 . 3 i}$

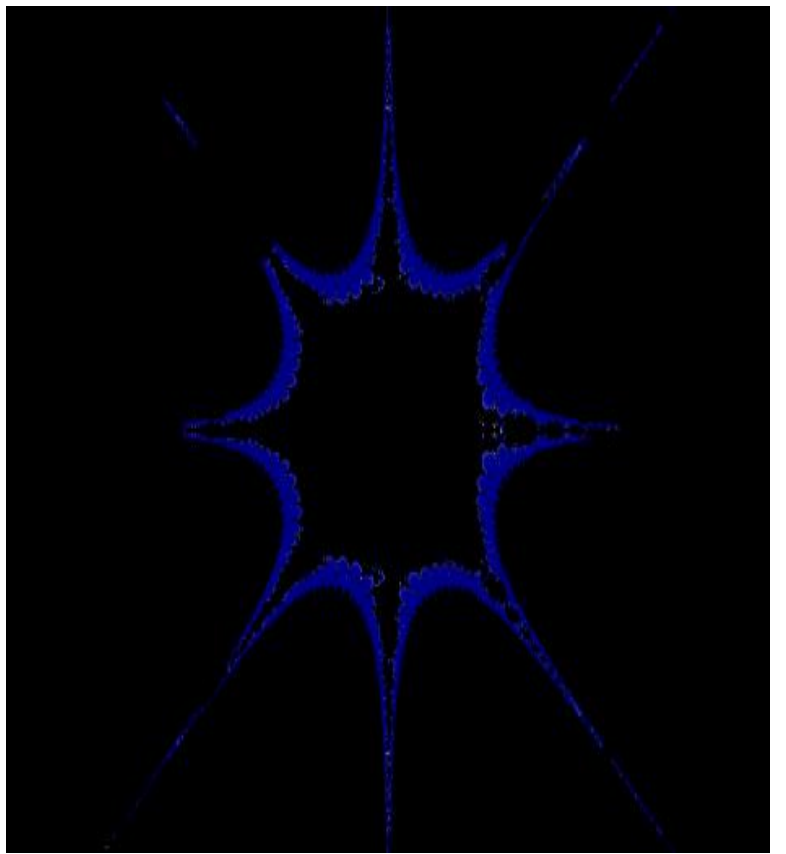

Figure 3: Relative Superior Julia Set for $\alpha=0.5, \beta=0.8$, $c=0.2375+0 \mathrm{i}$

\section{CONCLUSION}

In this paper we studied the sine function which is one of the members of transcendental family. The fixed point 0 for $\mathrm{S}(\mathrm{z})=\sin \left(\mathrm{z}^{\mathrm{n}}\right)-\mathrm{z}+\mathrm{c}=0$ also satisfies $\mathrm{S}^{\prime}(0)=1$. Orbits on the real axis tend to 0 while orbits on the imaginary axis tend to infinity. Relative Superior Julia Sets for the transcendental function $\sin (\mathrm{z})$ appears to follow law of having $2 \mathrm{n}$ wings.

The surrounding region of the Mandelbrot set appears to be an invariant Cantor set in the form of curve or "hair" that extends to $\infty$. The orbit of any point on hair tends to infinity under iteration. Here the geometry of hairs is quite similar to that of exponential family and hence showed the property of transcendental function. The region filled up with large number of escaping points represents Julia set plane.

\section{REFERENCES}

[1] Suman Joshi, Dr.Yashwant Singh Chauhan and Dr. Ashish Negi, "New Julia and Mandelbrot Sets for Jungck Ishikawa Iterates" International Journal of Computer Trends and Technology (IJCTT), vol.9, no.5, pp.209216, 2014.

[2] Suman Joshi, Dr.Yashwant Singh Chauhan and Dr.Priti Dimri "Complex Dynamics of Multibrot Sets for Jungck Ishikawa Iteration" International Journal of Research in Computer Applications and Robotics (IJRCAR), vol. 2, no. 4, pp. 12-22, 2014

[3] M.O.Olatinwo, "Some stability and strong convergence results for the Jungck-Ishikawa iteration process,"Creative Mathematics and Informatics, vol. 17, pp. 33-42, 2008.

[4] R. Chugh and V. Kumar, "Strong Convergence and Stability results for Jungck-SP iterative scheme, International Journal of Computer Applications, vol. 36,no. 12, 2011.

[5] S. Ishikawa, "Fixed points by a new iteration method", Proc. Amer. Math. Soc.44 (1974), 147-150. 
[6] G. Julia, "Sur 1' iteration des functions rationnelles", JMath Pure Appli. 8 (1918), 737-747

[7] B. B. Mandelbrot, The Fractal Geometry of Nature, W. H.Freeman, New York, 1983.

[8] Eike Lau and Dierk Schleicher, "Symmetries of fractals revisited." Math. Intelligencer (18) (1) (1996), 4551.MR1381579 Zbl 0847.30018.

[9] J. Milnor, "Dynamics in one complex variable; Introductory lectures", Vieweg (1999).

[10] Shizuo Nakane, and Dierk Schleicher, "Non-local connectivity of the tricorn and multicorns", Dynamical systems and chaos (1) (Hachioji, 1994), 200-203, World Sci. Publ., River Edge, NJ, 1995. MR1479931.

[11] Rajeshri Rana, Yashwant S Chauhan and Ashish Negi.Article: Non Linear Dynamics of Ishikawa
Iteration. International Journal of Computer Applications 7(13):43-49, October 2010. Published By Foundation of Computer Science.ISBN: 978-93-80746-97-5.

[12] Ashish Negi, "Generation of Fractals and Applications", Thesis, Gurukul Kangri Vishwvidyalaya, (2005).

[13] M.O.Osilike, "Stability results for Ishikawa fixed point iteration procedure", Indian Journal of Pure and Appl. Math., 26(1995), 937-945.

[14] A. G. D. Philip: "Wrapped midgets in the Mandelbrot set”, Computer and Graphics 18 (1994), no. 2, 239-248.

[15] Shizuo Nakane, and Dierk Schleicher, "On multicorns and unicorns: I. Antiholomorphic dynamics. Hyperbolic components and real cubic polynomials", Internat. J. Bifur. Chaos Appl. Sci. Engrg, (13) (10) (2003), 2825 2844. MR2020986. 